Marquette University

e-Publications@Marquette

College of Nursing Faculty Research and

Publications

Nursing, College of

$9-2020$

\title{
Engaging Parents in Education for Discharge (ePED): Evaluating the Reach, Adoption \& Implementation of an Innovative Discharge Teaching Method
}

\author{
Norah L. Johnson \\ Marquette University, norah.johnson@marquette.edu \\ Stacee M. Lerret \\ Medical College of Wisconsin \\ Carol Klingbeil \\ University of Wisconsin - Milwaukee \\ Michele Polfuss \\ Children's Hospital of Wisconsin \\ Cori A. Gibson \\ Children's Hospital of Wisconsin
}

See next page for additional authors

Follow this and additional works at: https://epublications.marquette.edu/nursing_fac

Part of the Nursing Commons

\footnotetext{
Recommended Citation

Johnson, Norah L.; Lerret, Stacee M.; Klingbeil, Carol; Polfuss, Michele; Gibson, Cori A.; Gralton, Karen; Garnier-Villarreal, Mauricio; Ahamed, Sheikh Iqbal; Adib, Riddhiman; Unteutsch, Rachel; Pawela, Louis; White-Traut, Rosemary; Sawin, Kathleen J.; and Weiss, Marianne E., "Engaging Parents in Education for Discharge (ePED): Evaluating the Reach, Adoption \& Implementation of an Innovative Discharge Teaching Method" (2020). College of Nursing Faculty Research and Publications. 716.

https://epublications.marquette.edu/nursing_fac/716
} 


\section{Authors}

Norah L. Johnson, Stacee M. Lerret, Carol Klingbeil, Michele Polfuss, Cori A. Gibson, Karen Gralton, Mauricio Garnier-Villarreal, Sheikh Iqbal Ahamed, Riddhiman Adib, Rachel Unteutsch, Louis Pawela, Rosemary White-Traut, Kathleen J. Sawin, and Marianne E. Weiss 
Marquette University

e-Publications@Marquette

\section{Nursing Faculty Research and Publications/College of Nursing}

This paper is NOT THE PUBLISHED VERSION; but the author's final, peer-reviewed manuscript. The published version may be accessed by following the link in the citation below.

Journal of Pediatric Nursing, Vol. 54 (September/October 2020): 42-49. DOI. This article is (C) Elsevier and permission has been granted for this version to appear in e-Publications@Marquette. Elsevier does not grant permission for this article to be further copied/distributed or hosted elsewhere without the express permission from Elsevier.

\section{Engaging Parents in Education for Discharge (ePED): Evaluating the Reach, Adoption \& Implementation of an Innovative Discharge Teaching Method}

Norah L. Johnson

College of Nursing, Marquette University, Milwaukee, WI

Children's Hospital of Wisconsin, Milwaukee, WI

Stacee Lerret

Children's Hospital of Wisconsin, Milwaukee, WI

Medical College of Wisconsin, Milwaukee, WI

Carol G. Klingbeil

College of Nursing, University of Wisconsin-Milwaukee, Milwaukee, WI

Michele Polfuss

Children's Hospital of Wisconsin, Milwaukee, WI

College of Nursing, University of Wisconsin-Milwaukee, Milwaukee, WI

Cori Gibson 
Children's Hospital of Wisconsin, Milwaukee, WI

\section{Karen Gralton}

Children's Hospital of Wisconsin, Milwaukee, WI

\section{Mauricio Garnier-Villarreal}

College of Nursing, Marquette University, Milwaukee, WI

\section{S. Iqbal Ahamed}

College of Nursing, Marquette University, Milwaukee, WI

\section{Adib Riddhiman}

College of Nursing, Marquette University, Milwaukee, WI

Rachel Unteutsch

Medical College of Wisconsin, Milwaukee, WI

\section{Louis Pawela}

Medical College of Wisconsin, Milwaukee, WI

\section{Rosemary White-Traut}

Children's Hospital of Wisconsin, Milwaukee, WI

\section{Kathy Sawin}

Children's Hospital of Wisconsin, Milwaukee, WI, United States of America

College of Nursing, University of Wisconsin-Milwaukee, Milwaukee, WI

\section{Marianne Weiss}

College of Nursing, Marquette University, Milwaukee, WI

\section{Abstract}

\section{Purpose}

This paper describes the evaluation of the implementation of an innovative teaching method, the "Engaging Parents in Education for Discharge" (ePED) iPad application (app), at a pediatric hospital.

\section{Design and methods}

The Reach, Effectiveness, Adoption, Implementation, and Maintenance (RE-AIM) framework was used to guide the evaluation. Three of the five RE-AIM elements are addressed in this study: Reach, Adoption, and Implementation.

\section{Results}

The Reach of the ePED was 245 of 1015 (24.2\%) patient discharges. The Adoption rate was 211 of 245 (86\%) patients discharged in the five months' study period. High levels of fidelity (89.3\%) to Implementation of the ePED were attained: the Signs and Symptoms domain had the highest (93\%) and Thinking Forward about Family Adjustment screen had the lowest fidelity (83.3\%). Nurse themes explained implementation fidelity: "It takes longer", and "Forgot to do it."

\section{Conclusions}

The ePED app operationalized how to have an engaging structured discharge conversation with parents. While the Reach of the ePED app was low under the study conditions, the adoption rate was positive. Nurses were able to integrate a theory-driven practice change into their daily routine when using the ePED app. 


\section{Implications for practice}

The rates of adoption and implementation fidelity support the feasibility of future hospital wide implementation to improve patient and family healthcare experience. Attention to training of new content and the interactive conversation approach will be needed to fully leverage the value of the ePED app. Future studies are needed to evaluate the maintenance of the ePED app.

\section{Keywords}

REAIM, Family engagement, Discharge teaching, Implementation evaluation

\section{Introduction}

Efforts to improve hospital discharge outcomes include strategies to build nurses' teaching skills for high-quality delivery of discharge teaching (Weiss et al., 2017). Engaging families in preparing for discharge helps them to recall and draw upon discharge teaching when needed at home (Berger, Flickinger, Pfoh, Martinez, \& Dy, 2014). Prior research shows that it is not the content of the discharge teaching alone, but the nurses skillful delivery of the content through parent engagement, that best prepares parents to care for their children (Weiss et al., 2008; Weiss et al., 2017). High quality discharge teaching leads to greater readiness for discharge, better postdischarge coping, and avoidance of post-discharge problems that result in unscheduled provider visits or readmission (Weiss et al., 2008, Weiss et al., 2017). When families are unable to follow discharge instructions and recognize post-hospitalization complications, they are more likely to utilize health care services such as the emergency room and to be readmitted for complications (Solan et al., 2015).

Parent comprehension of discharge instructions is affected by several dynamics such as previous adverse childhood experiences (Shah et al., 2018), health literacy of the teaching materials and how the teaching is delivered, and parents being in a hurry to get home (Koh, Brach, Harris, \& Parchman, 2013; Kornburger, Gibson, Sadowski, Maletta, \& Klingbeil, 2013). Nurses report feeling unprepared to teach and lack confidence in their ability to provide the education parents need for self-management at home following discharge (Lahl, Modic, \& Siedlecki, 2013). The content of patient teaching tends to be based on the nurse's practice-based experience rather than driven by evidence (Friberg, Granum, \& Bergh, 2012). In addition, nurse's knowledge of content and preparation in pedagogical skills is generally minimal (Friberg et al., 2012).

\section{Engaging parents in education for discharge (ePED)}

With an overall goal of improving discharge teaching experiences for parents and nurses' discharge teaching effectiveness, a Family Self-Management Discharge Preparation Intervention (FSM-DPI) iPad application (app) was developed (Sawin et al., 2017) and pilot tested (Weiss et al., 2017) by our research team to assist clinical nurses in preparing families to manage the care for their child at home after hospitalization. With responses from nurses that the app was comprehensive but realistically too long for routine clinical use, we refined it from nine to five domains and renamed it 'Engaging Parents in Education for Discharge' (ePED). The development of the FSM-DPI and the app are informed by the mid-range Individual and Family Self-Management Theory (IFSMT) (Ryan \& Sawin, 2009; Self Management Science Center at UWM, 2019), Tanner's Model of Clinical Judgement (Tanner, 2006), and an expanded "Teach Back" methodology (Agency for Healthcare Research and Quality, 2017). The ePED app integrates all three frameworks into the discharge teaching tool in the form of a structured guide for the discharging nurse to use in an interactive discharge conversation with parents.

The process of self-management involves the assessment of risks and complexities as well as the strengths of the family in preparing to manage the child's condition as they transition from hospital to home (Sawin et al., 2017). The key process components of the IFSMT are knowledge and beliefs, self-regulation, and social facilitation (Ryan \& Sawin, 2009). Parents need the knowledge and skills to manage the child's health at home 
and a positive belief in their own self-efficacy to be successful in care of the child at home. In the context of hospital discharge self-regulation refers to family preparation for adjustment to new demands and routines. Social facilitation refers to the availability of family, friends, and health professionals who are accessible for emotional and social support. These processes ultimately impact the overall ease or difficulty experienced during transitions from hospital to home. The content of discharge teaching embedded within the ePED app addressed each of these processes.

Tanner's Model of Clinical Judgement (Tanner, 2006) is embedded in the app as an iterative process of interaction between the nurse and the parent. Tanner's model points out that reflective nurses notice problems, interpret the child/family behavior, respond with appropriate action, read the family's response to nursing actions, and adjust their actions accordingly (Tanner, 2006). The ePED app supports nurses in using their expertise and clinical judgement in response to parent feedback from the app questions.

The Teach-Back Method [Agency for Healthcare Research and Quality (AHRQ), 2017] is integrated in the delivery method of the ePED app, shifting the focus to a more interactive conversation rather than an informational mode of communication during teaching. With teach-back, families are asked to explain or show the nurse what they have learned so the nurse can uncover lack of understanding and have the chance to provide clarification (AHRQ, 2017).

The purpose of this study was to evaluate the implementation of the ePED app as a tool to use in clinical practice to assist nurses in performing discharge teaching for parents of hospitalized children. RE-AIM (Reach, Effectiveness, Adoption, Implementation, and Maintenance) (Glasgow, Klesges, Dzewaltowski, Estabrooks, \& Vogt, 2006), an implementation science framework, was used as the organizing structure for this study. 'Reach' measures the representativeness of the target population. 'Effectiveness' measures outcomes. 'Adoption' measures participation by those who deliver the intervention. 'Implementation' assesses fidelity to the process or protocol. 'Maintenance' measures the extent to which the intervention becomes part of the routine operational practices (Glasgow et al., 2006).

\section{Methods}

This implementation study is part of a larger two group pre/post-test quasi-experimental study designed to improve the quality of discharge teaching, care coordination and post-hospital outcomes on two inpatient units at a large free-standing Midwest pediatric academic hospital (Lerret et al., 2020). Using the RE-AIM framework, we evaluated four of the five elements of the framework: (1) Reach, (2) Effectiveness, (3) Adoption, and (4) Implementation of the ePED app, three of which are reported here (Reach, Adoption, and Implementation; Effectiveness was reported in Lerret et al., 2020). Measurement of the RE-AIM constructs is outlined in Table 1.

Table 1. Measurement of RE-AIM constructs.

\begin{tabular}{|l|l|l|l|}
\hline RE-AIM element & $\begin{array}{l}\text { Glasgow et al. } \\
\text { (2006) definition }\end{array}$ & Study definition & Data sources/measures \\
\hline Reach $^{\text {a }}$ & $\begin{array}{l}\text { The percent and } \\
\text { representativeness of } \\
\text { individuals willing to } \\
\text { participate. }\end{array}$ & $\begin{array}{l}\text { The extent to which } \\
\text { parents of children } \\
\text { scheduled for discharge } \\
\text { participated in the study. }\end{array}$ & $\begin{array}{l}\text { Number and percent of } \\
\text { participants in the study and } \\
\text { the number of discharges on } \\
\text { the units in the five study } \\
\text { months. }\end{array}$ \\
\hline Effectiveness & $\begin{array}{l}\text { The impact of the } \\
\text { intervention on targeted } \\
\text { outcomes. }\end{array}$ & $\begin{array}{l}\text { The impact of the } e \text { PED } \\
\text { app on parent outcomes } \\
\text { at discharge. }\end{array}$ & $\begin{array}{l}\text { Parent perception of quality of } \\
\text { discharge teaching and care } \\
\text { coordination. }\end{array}$ \\
\hline Adoption $^{\text {a }}$ & $\begin{array}{l}\text { The percent and } \\
\text { representativeness of }\end{array}$ & $\begin{array}{l}\text { The frequency with } \\
\text { which nursing staff used }\end{array}$ & $\begin{array}{l}\text { Of enrolled parents, rate of } \\
\text { completion of the } e \text { PED app. }\end{array}$ \\
\hline
\end{tabular}




\begin{tabular}{|l|l|l|l|}
\hline & $\begin{array}{l}\text { settings and intervention } \\
\text { staff that agree to deliver } \\
\text { the program. }\end{array}$ & $\begin{array}{l}\text { the } \text { ePED app for } \\
\text { preparing parents for } \\
\text { discharge. }\end{array}$ & \\
\hline Implementationa $^{\text {a }}$ & $\begin{array}{l}\text { The consistency and skill } \\
\text { with which various program } \\
\text { elements are delivered by } \\
\text { various staff. }\end{array}$ & $\begin{array}{l}\text { The fidelity of the nurses } \\
\text { in the use of specific } \\
\text { components of the } e \text { PED } \\
\text { app. } \\
\text { Barriers and facilitators } \\
\text { to use of the } \text { PED app } \\
\text { implementation. }\end{array}$ & $\begin{array}{l}\text { 1. The of items per screen } \\
\text { where the nurse recorded } \\
\text { asking the } e \text { PED app questions } \\
\text { and recorded parent response. } \\
\text { 2. Interviews conducted by } \\
\text { research team with clinical } \\
\text { nurses on the units during the } \\
\text { first six weeks of the } \\
\text { implementation of the } e \text { PED } \\
\text { app. }\end{array}$ \\
\hline Maintenance & $\begin{array}{l}\text { The extent to which } \\
\text { individual participants } \\
\text { maintain behavior change } \\
\text { long term. }\end{array}$ & $\begin{array}{l}\text { The extent to which the } \\
\text { organization sustained } \\
\text { the implementation } \\
\text { after the study ended. }\end{array}$ & $\begin{array}{l}\text { To be evaluated in the future } \\
\text { based on decision to revise and } \\
\text { introduce into routine practice. }\end{array}$ \\
\hline
\end{tabular}

addressed in this study.

Study team members developed content for the ePED iPad app, staff training on the app, and the data collection process for the use of the app. The study was approved by the Institutional Review Board (IRB) as an implementation study at the freestanding children's hospital that served as the study site. Parents received an information sheet explaining the study components. Data were collected from September 2018-January 2019.

\section{Participants}

This study was conducted on two units; a 24-bed surgical unit served as the implementation unit for the ePED and the a 24-bed medical unit served as the usual discharge teaching control unit. All staff nurses on each of two units (45 nurses per unit) participated regardless of education or length of employment. The ePED app was used to prepare $(n=211)$ parents of children with acute, chronic and complex health conditions who were anticipating discharge to home from the implementation unit. On the control unit, $(n=184)$ parents received usual discharge teaching, which involves review of discharge papers and any additional information specific to patient needs. Parents on both units $(n=395)$ completed study questionnaires via an iPad interface to a REDCap database as part of the larger study (Lerret et al., 2020).

\section{Development of the ePED iPad application}

The development of the ePED app was as a collaborative effort between computer scientists and the nurse experts on the study team who refined the FSM-DPI app. Aligning this work with the study hospital's current discharge improvement initiative known as 'SMART,' as well as health literacy strategies offered the opportunity to align the ePED app within the context of the current discharge framework at the hospital. 'SMART' is an acronym for five essential elements of the discharge preparation: Signs and symptoms to watch for, Medications, Appointments, Results, and Talking about other diet, activity, and care needs specific to the patient. Alignment opportunities helped foster shared understanding for nurses during this practice change and maximized the likelihood of adoption (Lukas et al., 2007). Nurses were familiar with the SMART framework as it was part of health system-wide required safety training, including new nurse orientation classes and online training modules. For consistency, the five domains of the ePED app were labelled to align with the SMART acronym: (1) Signs and symptoms, (2) Medications, (3) Appointments and results, (4) Recovery and (5) Thinking forward to family adjustment. 
The ePED app consists of five screens, one for each of the SMART domains. After introducing the intervention to the parent and opening the app, the nurse worked through the five screens prompted by specific questions (see Table 3).

The nurse recorded all responses on the iPad. In addition to the questions for leading the conversation, each of the $e P E D$ screens included additional components to guide the nursing discharge teaching process in evaluating the parent responses during the conversation, specifically asking the nurse to evaluate the parent's knowledge and understanding of discharge preparation needs and appropriateness of their plan for care at home. These questions supported the use of an interactive and reflective process for discharge teaching (see Table 4). Once the ePED app itself was ready, the logistics of entering data and, dealing with interruptions in the discharge process and the flow of data into the database were trialed and evaluated by the research team prior to implementation.

\section{Nurse training}

A sub-group of two nurse scientists, one staff nurse, and one education specialist from the Education Department created and tested the training for the implementation and control units in this study. Online nurse training was provided on both the ePED app and performing high quality discharge teaching for the nurses on the implementation unit. Training was provided to nursing staff one month before the implementation of the ePED app study. Nurses on both the implementation and control units received training in parent recruitment and use of the iPad for collection of outcome questionnaires used for effectiveness measurement. All Registered Nurses employed on the implementation unit $(n=45)$ and the control unit $(n=45)$ completed their respective mandatory training.

Guided by the principle in self-efficacy theory of using vicarious experience to foster confidence (Bandura, 1977), the online training module included video role modelling of the nurse's use of the five domains of the $e$ PED app. Short, frequent, 'check your knowledge' questions were used to confirm understanding of newly learned key concepts to improve learner retention and later retrieval of the information (Roediger III, Putnam, \& Smith, 2011).

Additional support tools were created for the implementation unit that included a Just in Time (JIT) document that detailed for staff the introduction to the ePED implementation, enrollment in the study, and follow-up study questions. JIT training provides easily available need-to-know information about a specific task strategy focused on meeting the learner's need when it arises (Brandenburg \& Ellinger, 2016). Screen captures of the ePED app were printed and used as JIT support on the unit. All materials were organized in a binder so that research assistants and research nurses were able to refer and show nurses how to implement the intervention during daily rounding on the units involved in the study. A JIT on data entry only was created for the control unit.

Both units also received training on the process of accessing the two parent self-report questionnaires used as study effectiveness measures through the iPad. The Quality of Discharge Teaching Scale (Weiss et al., 2017) measures parent perception of how well nurses provide discharge teaching (Weiss et al., 2017), including items that assess how well nurses listened to and answered specific questions and concerns, expressed sensitivity to personal beliefs and values, taught in a manner that the parent could understand and at times that were good for parents, provided consistent information, promoted confidence in ability to care for the child, knew what to do in an emergency, and decreased anxiety about going home. The Care Transition Measure (Coleman et al., 2002), measures care coordination during the discharge transition in four domains: transfer of information, preparation of patient/caregiver, self-management support, and empowerment to address preferences. Reliability and validity of both tools has been supported in research with children (Lerret \& Weiss, 2011; Lerret, Weiss, Stendahl, et al., 2015). 


\section{Data analysis}

Data analysis was organized according to the elements of the RE-AIM framework (Table 1). Reach, Adoption, and Implementation are reported in this paper. Evaluation of Effectiveness of the ePED app in improving parent discharge outcomes, specifically their perception of the quality of discharge teaching and care coordination, is reported in detail separately (Lerret et al., 2020). Maintenance was not measured or analysed in this study.

Reach of the implementation of the ePED app was evaluated by calculating the proportion of eligible parents of children scheduled for discharge from the implementation unit who were approached and asked by nurses to participate in the study. For comparison, we also calculated the proportion of parents on the control unit who agreed to enroll for the purpose of providing outcome measures only. Adoption of the use of the ePED app by nursing staff was evaluated by calculating the proportion of enrolled parents where the nurse fully completed the discharge teaching using the app. The Implementation of the app was evaluated by assessing the fidelity of the nurses to the implementation protocol by determining the proportion of parents with whom all components of the app were completed as instructed. The number of button clicks on the app was captured, which indicates whether or not the questions were asked, the type of feedback provided, parent responses to the guiding questions, and actions taken by the nurse based on parent responses.

Fidelity was also evaluated through thematic analysis of informal interviews conducted with the implementation unit nurses. A research study team member made daily rounds during the first six weeks of the roll out of the ePED app and approached all nurses for verbal feedback in addition to written feedback that the nurses provided in the unit study log book. Thirty nurses provided comments. Interviews focused on the nurses' perceptions about the intervention and facilitators and barriers to use in the practice setting. No demographic data was collected on the nurses.

\section{Results}

Table 2 presents the results of evaluation of Reach and Adoption. The Reach of the ePED app was 245 of the 1015 parents (24.2\%) who started to use the ePED app on the implementation unit over the five months study period. Although the nurses approached 245 parents, a total of 211 completed the discharge with the app and completed the study questionnaires on the iPad, meaning that the nursing staff adopted the format with $86 \%$ of parents who agreed to participate. As a point of comparison, 21\% (184 of 861) of families discharged on the control unit, without the app, were reached (enrolled) in the study. We recorded the number of parents who declined participation in the study and the reasons for declining. The rate of decline was $14.9 \%$ (151 of 1015) of parents on the implementation unit and $14.5 \%$ (125 of 861 ) of parents on the control units. The remaining $85.1 \%$ (864 of 1015) of parents on the implementation unit and $85.5 \%$ (736 of 861 ) of parents on the control units were not asked to participate.

Table 2. Reach and adoption of the ePed app ( $\mathrm{N}=$ number of parents).

\begin{tabular}{|l|l|l|}
\hline & $\begin{array}{l}\text { Implementation unit N } \\
(\%)\end{array}$ & Control unit N (\%) \\
\hline Discharges during time period of the study & 1015 & 861 \\
\hline Parents enrolled in the study & $211(20.8)$ & $184(21.4)$ \\
\hline Parents not enrolled in study & $804(79.2)$ & $677(78.6)$ \\
\hline $\begin{array}{l}\text { Documented reason for decline of } \\
\text { participation }\end{array}$ & $151(18.8)$ & $125(18.5)$ \\
\hline $\begin{array}{l}\text { Reason for declines (multiple responses } \\
\text { permitted) }\end{array}$ & & \\
\hline Parent related reasons & & $71(56.8)$ \\
\hline Not enough time & $61(40.4)$ & \\
\hline
\end{tabular}




\begin{tabular}{|l|l|l|}
\hline Need to get home to other children & $13(8.6)$ & $3(2.4)$ \\
\hline Distractions with other children & $1(0.1)$ & 0 \\
\hline Mother anxious, child too active & $5(3.3)$ & 0 \\
\hline Long drive home & $4(2.6)$ & 0 \\
\hline Late night discharge; family exhausted & $1(0.1)$ & 0 \\
\hline Family didn't want to wait & $2(1.3)$ & $1(0.8)$ \\
\hline Already participated- ineligible & $4(2.6)$ & $2(1.6)$ \\
\hline Patient in isolation & $4(2.6)$ & $3(2.4)$ \\
\hline Nurse related reasons & & \\
\hline Float nurse with no training & $6(3.9)$ & $2(1.6)$ \\
\hline Forgot to ask & $1(0.1)$ & $2(1.6)$ \\
\hline Issues with the technology & $2(1.3)$ & 0 \\
\hline
\end{tabular}

The primary reason for non-participation in both the implementation and control group were parent focused including 'not enough time' and 'needing to get home to other children' (Table 2). There were very few nursing related reasons for failure to use the ePED app identified by the nurses, though examples included: 'trouble with the iPad technology' and a 'nurse floating to the unit with no training on the study.'

Implementation fidelity was measured as the frequency with which the nurses used the three major components of nurse-parent interaction guided by the ePED app: (1) Guiding questions asked by the nurse to stimulate the interview, (2) Parent responses to the guided interview were evaluated by the nurse, (3) Nurse response to the parent responses by documenting one or more nurse actions. All questions in the five domains of the app were asked with high frequency. Signs and Symptoms and the Medication domains had the highest fidelity at $85-97 \%$ ( $n=211$ to $n=239$ ), with the thinking forward about family adjustment having the lowest at 77-93\% ( $n=190$ to $n=229$ ) (Table 3).

Table 3. Implementation Fidelity: did the nurse ask the guiding questions? ( $N=245$ parents).

\begin{tabular}{|l|l|l|}
\hline Questions on the & $\begin{array}{l}\text { Question } \\
\text { asked }\end{array}$ & \\
\hline & $\mathbf{N}$ & $\%$ \\
\hline I. Signs \& symptoms & & 97 \\
\hline 1. Tell me how you would know if your child is not doing well? & 239 & 92 \\
\hline 2. What will you watch for? & 227 & 85 \\
\hline 3. What will you do to keep track of these things? & 211 & 95 \\
\hline $\begin{array}{l}\text { 4. I want to be sure that you know when to call your doctor or nurse when you go } \\
\text { home. Tell me what situations would make you want to call your nurse or doctor? }\end{array}$ & 234 & 95 \\
\hline 5. What worries or concerns do you have about caring for your child a home? & 234 & 94 \\
\hline 6. What other questions do you have? & 231 & \\
\hline II. Medications & & 94 \\
\hline 1. Name and reason for taking & 232 & 87 \\
\hline 2. Dose and side effects & 215 & 91 \\
\hline 3. Time of administration & 224 & 92 \\
\hline 4. What is your plan for getting the medications for home? & 226 & \\
\hline III. Appointments \& results & & 92 \\
\hline 1. How will you plan to get to your child's follow-up lab/ clinic appts? & 227 & 83 \\
\hline 2. What results are you still waiting for? & 204 & \\
\hline IV. Recovery & & \\
\hline
\end{tabular}




\begin{tabular}{|l|l|l|}
\hline $\begin{array}{l}\text { 1. Tell me about your child's normal activities e.g. getting up, eating, going to school or } \\
\text { day care. }\end{array}$ & 228 & 93 \\
\hline $\begin{array}{l}\text { 2. How will you decide when your child can return to regular activities like school and } \\
\text { sports? }\end{array}$ & 212 & 86 \\
\hline 3. What is your plan for day care, sports, driving, school notes, and excuses? & 214 & 87 \\
\hline V. Think forward: family adjustment & & \\
\hline $\begin{array}{l}\text { 1. In taking your child home from the hospital, what adjustments will you make? } \\
\text { 2. Have you thought about changes you and your family will have to make for your } \\
\text { other children, your job, childcare and/or other family members? }\end{array}$ & 229 & 93 \\
\hline $\begin{array}{l}\text { 3. There will be things that other caregivers will need to learn. How will they learn } \\
\text { them and when? }\end{array}$ & 190 & 77 \\
\hline $\begin{array}{l}\text { 4. Who can you count on to give you emotional support if you are worried or } \\
\text { stressed? }\end{array}$ & 204 & 80 \\
\hline
\end{tabular}

In evaluating parent responses to the interactive discharge conversation, each screen of the ePED app was evaluated independently (Table 4). The nurses recorded 'yes' on each screen when the parent verbalized correct information. For the first four screens, the nurses noted that the parents almost always verbalized correct information for the Signs and Symptoms screen [ $n=238$ (97\%)], Medications [ $n=237$ (96\%)], Appointments $[n=237(96 \%)]$, and Recovery $[n=237(96 \%)]$. Only a small number of parent responses $[n=7(3 \%)$ to $n=8$ (4\%)] were recorded by the nurses as either 'incorrect/unsure', or had 'no understanding' for these screens of the $e$ PED app. For the fifth screen, which involved thinking forward to family adjustment at home after discharge, the nurses documented that 204 (83\%) of parents verbalized a specific plan for caring for the child at home, compared to $41(17 \%)$ with partial, vague, or unrealistic plans.

Table 4. Implementation Fidelity: percent of patients with: (1) an assessment of parent response and (2) RN response to the parent recorded by the nurse in the app ( $N=245$ parents).

\begin{tabular}{|l|l|l|l|l|l|}
\hline & $\begin{array}{l}\text { 1. Signs \& } \\
\text { symptoms }\end{array}$ & $\begin{array}{l}\text { 2. } \\
\text { Medications }\end{array}$ & $\begin{array}{l}\text { 3. Appointments } \\
\text { \& results }\end{array}$ & $\begin{array}{l}\text { 4. } \\
\text { Recovery }\end{array}$ & $\begin{array}{l}\text { 5. Think } \\
\text { forward: family } \\
\text { adjustment }\end{array}$ \\
\hline & Sum (\%) & Sum (\%) & Sum (\%) & Sum (\%) & Sum (\%) \\
\hline $\begin{array}{l}\text { 1. a. Parent verbalized } \\
\text { correct information-Yes }\end{array}$ & $238(97)$ & $237(96)$ & $237(96)$ & $237(96)$ & - \\
\hline $\begin{array}{l}\text { b. Parent verbalized a } \\
\text { specific plan-Yes }\end{array}$ & - & - & - & - & $204(83)$ \\
\hline $\begin{array}{l}\text { 2. RN response to parent } \\
\text { (Screen1-4) }\end{array}$ & & & & & - \\
\hline Positive reinforcement & $206(84)$ & $202(82)$ & $196(80)$ & $195(79)$ & \\
\hline Supplemental information & $98(40)$ & $91(37)$ & $69(28)$ & $67(27)$ & - \\
\hline Extensive teaching & $66(27)$ & $67(27)$ & $60(24)$ & $57(23)$ & - \\
\hline Corrected information & $69(28)$ & $69(28)$ & $62(25)$ & $62(25)$ & - \\
\hline $\begin{array}{l}\text { Provide additional } \\
\text { resources }\end{array}$ & $75(30)$ & $68(27)$ & $64(26)$ & $62(25)$ & - \\
\hline $\begin{array}{l}\text { RN response to parent } \\
\text { (Screen 5) (multiple } \\
\text { responses permitted) }\end{array}$ & & & & & \\
\hline $\begin{array}{l}\text { 1. Provided validation of } \\
\text { plan }\end{array}$ & - & & - & - & \\
\hline
\end{tabular}




\begin{tabular}{|l|l|l|l|l|l|}
\hline $\begin{array}{l}\text { 2. Worked with parent to } \\
\text { identify a plan - parent } \\
\text { engaged in planning }\end{array}$ & - & - & - & - & $197(80)$ \\
\hline $\begin{array}{l}\text { 3. Worked with parent to } \\
\text { identify a plan - parent } \\
\text { not engaged in planning }\end{array}$ & - & - & - & - & $85(35)$ \\
\hline $\begin{array}{l}\text { 4. Reviewed options - e.g. } \\
\text { Home Health }\end{array}$ & - & - & - & - & $67(27)$ \\
\hline
\end{tabular}

For the final part of the nurse-parent interaction, nurse response to the parent, $e P E D$ app screens one through four (Signs and Symptoms, Medications, Appointments, Recovery) also had different response options than screen five (Thinking forward on Family Adjustment). For screens one through four, positive reinforcement was the highest recorded nursing action, documented for 195 (79\%) parents in the Recovery screen and 206 (84\%) of parents in the Signs and symptoms to watch screen. For screens one through four, one-quarter of parents $[n=57(23 \%)$ to $n=67(27 \%)]$, nurses offered additional teaching even though the parent had identified an appropriate plan. For another one-quarter of parents $[n=63(25 \%)$ to $n=69(28 \%)]$, nurses noted that they needed to correct parent information.

Validation for the parents' plan in the fifth screen (Thinking forward about family adjustment) was the most common nurse action in response to the parent $[n=227(92 \%)]$. Nurses could indicate multiple responses. A large number of the nurses noted that even when parents indicated a validated plan, additional time was needed to discuss the discharge plan for home $[n=197(80 \%)]$. This finding may be the result of planning efforts for complex patients that require a multicomponent plan of care for discharge or a function of the nurses unfamiliarity with asking the question. A smaller but substantial number of parents $[n=85,(35 \%)]$ were recorded to be not engaged with nurses during planning; this rate of non-engagement is concerning.

Nurse interviews conducted during the initial six weeks of the roll out of the implementation revealed two themes about the nurse reaction to using the ePED app that had an impact on intervention fidelity: (1) "It takes longer" and (2) "Forgot to do it." In terms of the length of time to use the app for the discharge, all nurses agreed that it took more time than their usual discharge process. Feedback about this extra time varied across nurses. One nurse stated, "It takes her a few minutes longer to do the discharge with the app." In contrast, another nurse summed it up as "time intensive." Another nurse stated: "It is taking more time than I thought it would... but she (the mother) was very nice and didn't mind the time." Nurses did not think the app was necessary for simple discharges. One nurse noted that she had a routine already for simple discharges such as tonsillectomy and that "any change adds more time and makes them have to do it differently so that is not appreciated."

The second theme was "forgot to do it". With competing priorities and distractions some nurses simply did not remember to implement the ePED app for discharge.

One nurse stated "I remembered when a study team member was doing rounds asking at the desk if there were any discharges" and further stated "When I forgot about the intervention, I felt really bad." A charge nurse on the implementation unit noted that the "nurses just need constant reminders" to use the app. She thought that using the app the first time was the biggest challenge. She "reminded staff that there was an ePED 'test' or 'practice' environment" on the iPads where they could practice using the app before using it with a parent. One nurse noted the presence of the research team in encouraging the use of the ePED app: "I took the iPad and paperwork into the room because the research assistant was still here [on the unit]". 


\section{Discussion}

Testing the implementation of a new nursing practice is complex with factors associated with nurse and parent priorities affecting the Reach, Adoption, Implementation and ultimately the Effectiveness of the practice change. In this study, only one quarter of the eligible parents discharged over five months' time were reached with the practice change. However, nurses were able to adopt it at a high rate for those who actually enrolled in the study. The similar rate of Reach in the control group of parents suggests that, while nurses and parents found the ePED sufficiently acceptable to adopt it at a high rate once study enrollment had occurred, the low reach in accessing parents for participation was more likely related to the time required for study participation rather than acceptability of the ePED app itself.

Time pressure is a barrier for the day of discharge teaching (Koh et al., 2013; Kornburger et al., 2013). In the present study, parents and nurses completed the screens with high frequency, despite their perception that it required additional time over typical discharge teaching, but nurses reported in interviews that the practice change was time intensive within the constraints of competing demands. Parents cited competing demands of having long drives home, and having other children with them or at home that needed their attention as reasons for refusal to participate. Unstated parent and nurse reasons for non-participation in the new teaching approach may have also included not wanting to participate in research or lack of comfort with the iPad entry of study data. This finding speaks to the reality of the challenge of engaging parents in day of discharge teaching.

While discharge teaching begins on admission and is a fundamental component of care throughout the hospitalization (Berry et al., 2014), the day of discharge is a time to validate preparation for the discharge transition and supplement or reinforce teaching as needed. Effective patient teaching results from patient engagement, andragogical/pedagogical learning principles, motivational interviewing, and teach-back methods (Candela, Piacentine, Bobay, \& Weiss, 2018). The IDEAL discharge model (AHRQ, n.d. identifies five essential components of the discharge process: Include the patient and family; Discuss key areas to prevent problems at home; Educate in plain language; Assess understanding using teach back; Listen to and honor goals, preferences, observations, and concerns [IDEAL (AHRQ, n.d.)]. These guidelines each advocate for an interactive teachinglearning style to prepare patients for discharge.

In terms of evaluation of implementation fidelity, nurses appeared to be most comfortable asking questions on the first four screens of the ePED app. The final screen of questions on the app had questions on 'Thinking forward about family adjustment' question, and this screen had the lowest fidelity. The 'Thinking forward' content is not traditionally a part of discharge teaching, while the other parts are more familiar to nurses. To effectively use the ePED app, nurses will need better preparation in interactive discharge conversations (Candela et al., 2018), that includes thinking forward to family adjustment.

The ePED app guided nurses in an iterative, interactive process of assessment using probing questions, followed by assessment of parent responses, and nurse actions in response to parent responses. This iterative process operationalized Tanner's Model of Clinical Judgement in Nursing (Tanner, 2006) of noticing or developing a perception of the situation, interpreting or developing an understanding of the situation, responding by implementing the best course of action for the situation; and reflecting evaluating with the family to determine whether or not the actions need to be revised. The validation or assistance with developing the plan for returning home is an example of the clinical application of Tanner's Model. The nurse assesses the risks, complexities and the strengths of the family in managing the child's condition and transition home and provides feedback. This reflective opportunity creates a window for the nurse to provide valuable feedback to parents about their planning (Sawin et al., 2017; Tanner, 2006). Nurses play a key role in helping families to anticipate the impact of the transition home on the behavior of the child and family routines. Parents are encouraged to 
monitor their child, contact health providers with concerns, and to use their social support while adapting to the changes at home.

Positive reinforcement was the most common nurse action following parent responses. The use of the teach back approach within the ePED app contributed to nurses high rate of positive reinforcement and validation of correct information from parents as well as correcting information. Teach back is a method that promotes health literacy; in our study, using teach back assured that the parents understood how to perform the child's care and what complications to watch for and report back to the health care team. Reinforcement fostered confidence in the family's ability to manage care at home, a key process component of the IFSMT (Ryan \& Sawin, 2009). However, supplemental information, extensive teaching, corrected information and additional resources were employed with one quarter of parents.

Validation of the parents plan for care at home after discharge was the most common nurse action in the 'Thinking forward' domain. Thinking forward extends the teach-back method of restating knowledge and demonstrating back skills to projecting how this knowledge and skills obtained in preparation for discharge will actually be used once the parent and child are home. While most parents were engaged in planning for the transition home after discharge, nurses reported that one-third of parents were not engaged in this planning and the nurses needed to work on developing a plan with these parents. These findings highlight the importance of the interactive approach to discharge teaching to identify and address areas of discharge preparation that have not been completed by the day of discharge. The need for additional teaching, correction of information, and additional planning are not uncommon. Nurses need dedicated time for day of discharge teaching to assure that parents are fully prepared for discharge.

The themes that emerged in the nurse interviews points to potential next steps for the wider implementation of the ePED app. Some nurses noted that they did not remember to use the app. One nurse noted that she went ahead and used the app because a research team member was on the unit as a source of support. Training unit champions could stimulate better reach, adoption, and fidelity for the use of the ePED app. Another strategy could include adding role playing to the training to improve staff self-efficacy (Bandura, 1977). Moving beyond implementation within a research study to implementation as a standard practice for discharge will improve reach, adoption, and fidelity to implementation. Nevertheless, thorough training, clear expectations, leadership support, monitoring, and boosting of performance through continuing education is imperative for success (Friberg et al., 2012). Depending on the hospital environment, this may be an operational challenge.

Use of the RE-AIM framework for comprehensive evaluation of the implementation using mixed methods was a strength of this study. Aligning the content of the ePED app with the SMART acronym that was familiar to the nursing staff and training the nurses on the implementation unit produced a good adoption rate and fidelity to completion of the intervention components.

Limitations of the study included that implementation was restricted to two units as our goal was to assess feasibility and acceptability of the implementation prior to making recommendations for wider application. In addition, the differences in acuity and focus of the implementation and comparison units limited our interpretation of findings. Implementation as research, not as practice change, may have limited reach. Demographics were not collected on the nurses. Nurses floating to the intervention unit did not receive the training and were sometimes assigned to discharge patients, which limited participant enrollment. Maintenance of the intervention over time was not assessed in this study, but should be included in future studies. Length of time to complete the discharge process was not measured in this study, though perceptions related to increased time may have reduced adoption. In the future, efforts to increase reach, adoption, and fidelity will require collaboration with unit nurses and managers and providers to explore increased time allocation for discharge teaching and to integrate the intervention fully into usual discharge care practices before the day of discharge. 


\section{Conclusion}

The ePED app operationalized a process for nurses to have an engaging structured discharge conversation between a nurse and parents. While the Reach of the ePED was low, the Adoption rate was high indicating that nurses in this study were able to integrate a theory-driven implementation into their practice. Evaluation of the implementation points to the ease of use and high fidelity in asking questions about signs and symptoms, medication, appointments and recovery. A need for better preparation of nurses for a discharge conversation that includes helping the family think forward to the transition home was identified.

\section{Practice implications}

This study has implications for improving discharge teaching experiences for parents and nurses' discharge teaching effectiveness with the use of the ePED app. Findings of this study point to strategies to increase reach, support adoption, and assure fidelity when implementing similar interventions that coach and guide nurses through complex nursing interventions. The implementation of the ePED app contents as part of the electronic record could help increase the reach, adoption, and fidelity of implementation so that more parents of discharged children have access to high quality discharge teaching.

Findings about Adoption and Implementation of the ePED app show promise for future hospital-wide implementation to improve patient and family healthcare experience. Attention to training in new content and the interactive conversation approach will be needed to fully leverage the value of the ePED app. Future studies are also needed to evaluate the maintenance of the ePED app implementation of time as a standard practice for discharging hospitalized children.

\section{Acknowledgments}

We would like to acknowledge the following for their contribution and support: Tess Weinkauf, Amanda King, Brenna McGinn, Kari Bogdan, Unit nurses; Children's Hospital of Wisconsin operational support of Chief Nursing Officer and Vice President Nancy Korom and Vice President Lisa Jentsch.

\section{Funding}

This work was supported by the CTSI Pilot Collaborative Clinical and Translational Research Grants Program National Center for Advancing Translational Sciences (NCATS), National Institutes of Health (NIH), Award Number UL1TR001436. Additional funds were provided by the Pediatric Nursing Research Consortium, a joint project of Children's Hospital of Wisconsin, University of Wisconsin-Milwaukee College of Nursing and Marquette University College of Nursing.

\section{References}

Agency for Healthcare Research and Quality (AHRQ), n.d. Agency for Healthcare Research \& Quality (AHRQ). (n.d). Strategy 4: Care Transitions From Hospital to Home: IDEAL Discharge Planning. [internet]. Washington, DC: AHRQ. Available from: https://www.ahrq.gov/professionals/systems/hospital/engagingfamilies/strategy4/index.html.

Agency for Healthcare Research and Quality, 2017. Agency for Healthcare Research and Quality. The teach back method. Retrieved from https://www.ahrq.gov/professionals/quality-patient-safety/patient-familyengagement/pfeprimarycare/interventions/teach-back.html (2017)

Bandura, 1977. A. Bandura. Self-efficacy: Toward a unifying theory of behavioral change. Psychological Review, 84 (2) (1977), pp. 191-215

Berger et al., 2014. Z. Berger, T.E. Flickinger, E. Pfoh, K.A. Martinez, S.M. Dy. Promoting engagement by patients and families to reduce adverse events in acute care settings: A systematic review. BMJ Quality and Safety, 23 (7) (2014), pp. 548-555, 10.1136/bmjqs-2012-001769 
Berry et al., 2014. J.G. Berry, K. Blaine, J. Rogers, S. McBride, E. Schor, J. Birmingham, ..., C. Feudtner. A framework of pediatric hospital discharge care informed by legislation, research, and practice. JAMA Pediatrics, 168 (10) (2014), pp. 955-962. quiz 965-956. https://doi.org/10.1001/iamapediatrics.2014.891

Brandenburg and Ellinger, 2016. D.C. Brandenburg, A.D. Ellinger. The future: Just-in-time learning expectations and potential implications for human resource development. Advances in Developing Human Resources, 5 (3) (2016), pp. 308-320, 10.1177/1523422303254629

Candela et al., 2018. L. Candela, L. Piacentine, K. Bobay, M.E. Weiss. Teaching students to teach patients: A theory-guided approach. Journal of Nursing Education and Practice, 8 (11) (2018), pp. 92101, 10.5430/jnep.v8n11p92 URL: 10.5430/jnep.v8n11p92

Coleman et al., 2002. E.A. Coleman, J.D. Smith, J.C. Frank, T.B. Eilertsen, J.N. Thiare, A.M. Kramer. Development and testing of a measure designed to assess the quality of care transitions. International Journal of Integrated Care, 2 (1) (2002), pp. 1-9

Friberg et al., 2012. F. Friberg, V. Granum, A.L. Bergh. Nurses' patient-education work: Conditional factors-an integrative review. Journal of Nursing Management, 20 (2) (2012), pp. 170-186

Glasgow et al., 2006. R.E. Glasgow, L.M. Klesges, P. Dzewaltowski, P.A. Estabrooks, T.M. Vogt. Evaluating the impact of health promotion programs: Using the RE-AIM framework to form summary measures for decision making involving complex issues. Health Education Research, 21 (5) (2006), pp. 688-694

Koh et al., 2013. H.K. Koh, C. Brach, L.M. Harris, M.L. Parchman. A proposed "health literate care model" would constitute a systems approach to improving patients' engagement in care. Health Affairs (Millwood), 32 (2) (2013), pp. 357-367, 10.1377/hlthaff.2012.1205

Kornburger et al., 2013. C. Kornburger, C. Gibson, S. Sadowski, K. Maletta, C. Klingbeil. Using "teach-back" to promote a safe transition from hospital to home: An evidence-based approach to improving the discharge process. Journal of Pediatric Nursing, 28 (3) (2013), pp. 282-291, 10.1016/j.pedn.2012.10.007

Lahl et al., 2013. M. Lahl, M.B. Modic, S. Siedlecki. Perceived knowledge and self-confidence of pediatric nurses as patient educators. Clinical Nurse Specialist, 27 (4) (2013), pp. 188-

193, 10.1097/NUR.0b013e3182955703

Lerret et al., 2020. S.M. Lerret, N.L. Johnson, M. Polfuss, C. Klingbeil, C. Gibson, M. GarnierVillareal, ..., M.E. Weiss. Using the engaging parents in education for discharge (ePed) iPad application to improve parent experience. Journal of Pediatric Nursing, 52 (2020) (2020), pp. 4148, 10.1016/j.pedn.2020.02.041

Lerret and Weiss, 2011. S.M. Lerret, M.E. Weiss. How ready are they? Parents of pediatric solid organ transplant recipients and the transition from hospital to home following transplant. Pediatric Transplantation, 15 (6) (2011), pp. 606-616

Lerret et al., 2015. S.M. Lerret, M.E. Weiss, G.L. Stendahl, et al. Pediatric solid organ transplant recipients: Transition to home and chronic illness care. Pediatric Transplantation, 19 (1) (2015), pp. 118-129

Lukas et al., 2007. C.V. Lukas, S.K. Holmes, A.B. Cohen, J. Restuccia, I.E. Cramer, M. Shwartz, M.P. Charns. Transformational change in health care systems: An organizational model. Health Care Management Review, 32 (4) (2007), pp. 309-320, 10.1097/01.HMR.0000296785.29718.5d

Roediger III et al., 2011. H.L. Roediger III, A.L. Putnam, M.A. Smith. Ten benefits of testing and their applications to educational practice. (2011), pp. 1-36, 10.1016/b978-0-12-387691-1.00001-6

Ryan and Sawin, 2009. P. Ryan, K.J. Sawin. The individual and family self-management theory: Background and perspectives on context, process, and outcomes. Nursing Outlook, 57 (4) (2009), pp. 217-225 e216, 10.1016/i.outlook.2008.10.004

Sawin et al., 2017. K.J. Sawin, M.E. Weiss, N.L. Johnson, K. Gralton, S. Malin, C. Klingbeil, ..., R.F. Schiffman. Development of a self-management theory-guided discharge intervention for parents of hospitalized children. Journal of Nursing Scholarship, 49 (2) (2017), pp. 202-213, 10.1111/jnu.12284

Self-Management Science Center at UWM, 2019. Self-Management Science Center at UWM. Retrieved from https://uwm.edu/nursing/about/centers-institutes/self-management/theory/ (2019) 
Shah et al., 2018. A.N. Shah, A.F. Beck, H.J. Sucharew, S. Litman, C. Pfefferman, J. Haney, ..., Group, H. O. S. Parental adverse childhood experiences and resilience on coping after discharge. Pediatrics, 141 (4) (2018), 10.1542/peds.2017-2127

Solan et al., 2015. L.G. Solan, A.F. Beck, S.A. Brunswick, H.S. Sauers, S. Wade-Murphy, J.M. Simmons, ..., H.O. Study Group. The family perspective on hospital to home transitions: A qualitative study. Pediatrics, 136 (6) (2015), pp. e1539-e1549, 10.1542/peds.2015-2098

Tanner, 2006. C.A. Tanner. Thinking like a nurse: A research-based model of clinical judgment in nursing. The Journal of Nursing Education, 45 (6) (2006), pp. 204-211

Weiss et al., 2008. M.E. Weiss, N.L. Johnson, S. Malin, T. Jerofke, C. Lang, E. Sherburne. Readiness for discharge in parents of hospitalized children. Journal of Pediatric Nursing, 23 (4) (2008), pp. 282295, 10.1016/j.pedn.2007.10.005

Weiss et al., 2017. M.E. Weiss, K.J. Sawin, K. Gralton, N.L. Johnson, C. Klingbeil, S. Lerret, ..., R. Schiffman. Discharge teaching, readiness for discharge, and post-discharge outcomes in parents of hospitalized children. Journal of Pediatric Nursing, 34 (2017), pp. 58-64, 10.1016/j.pedn.2016.12.021 